Paper No. 2004-1198

\title{
Integrating Ethics into the Freshman Year Engineering Experience
}

\author{
Dr. George D. Catalano \\ Department of Mechanical Engineering \\ State University of New York at Binghamton
}

\begin{abstract}
Various attempts are described in an effort to integrate ethics into the freshman year engineering classes. The attempts include formal lectures on moral reasoning theories, ethics focused videos/DVDs, environmentally focused design projects, design projects that force students to consider societal and global issues. A somewhat different type of design project, Compassion Practicum, is also described. The Compassion Practicum requires students to use an engineering design methodology to identify, design a solution an implement that solution with the charge to the student stated as "do something compassionate for some being other than you."
\end{abstract}

\section{Introduction}

The Accreditation Board for Engineering and Technology (ABET), the organization which sets forth specific guidelines for attaining engineering program accreditation has written that "Engineering programs must demonstrate that their graduates have... an understanding of professional and ethical responsibility."1 The actual means for accomplishing these tasks are left to the individual programs, as are the working definitions of phrases such as "professional and ethical responsibility." In response to the ABET position, according to Shirley ${ }^{2}$, the American Society of Engineering Education (ASEE) in a policy statement proposes that, "New engineering graduates need substantial training in recognizing and solving ethical problems." Furthermore, ASEE has recently established an Engineering Ethics Committee and formed a new group focusing upon ethics in the Educational Research and Methods Division. Shirley ${ }^{2}$ also challenged all of us in engineering to "avoid engineering hubris" and asked, "How can we embed ethics in the curriculum in a way that gives students tools that they can really use after graduation? And how do we measure the effectiveness of this training?"

The increased focus upon professional ethics by both ABET and ASEE has resulted in a similar increased emphasis on this topic in engineering programs throughout the nation. Discussion of engineering ethics cases occurs at all levels throughout the curriculum though mainly within the context of freshman introduction to engineering

Proceedings of the 2004 American Society for Engineering Education

Annual Conference and Exposition

Copyright C2004, American Society for Engineering Education 
courses. With the increasing number of teaching resources available, many engineering courses appear use a case study approach, either of an existing historical event or a fictitious scenario, often with the requirement that students examine their proposed approaches to the described ethical dilemmas in light of existing codes of ethical and professional conduct set forth by the professional engineering societies.

While I agree that the use of case studies and the engineering codes is a valuable teaching technique and necessary if programs are to reflect the required emphasis placed on ethical training by both ABET and ASEE, I believe that it is not sufficient. Simply teaching to the case studies and using existing codes of conduct, in my view, promulgates a very narrow understanding of ethics and its importance in the engineering profession. Consider a somewhat similar situation. Suppose students were to have one and only one exposure to physics. Would it be "necessary and sufficient" to introduce students solely to Newtonian mechanics without reference to the important developments in the last two centuries? Perhaps some might argue that in selected engineering disciplines an introduction to Newtonian mechanics would be all that is required. I would contend that the practice of engineering is rapidly changing and that the classical foundation for engineering in the $19^{\text {th }}$ and $20^{\text {th }}$ century is no longer adequate for the $21^{\text {st }}$ century. Physics has moved far beyond the Newtonian paradigm.

Integrating or embedding ethics into the engineering curriculum can be interpreted at many different levels of meaning. Using the schema proposed by Dante Alighieri in his study of Exodus, there are at a minimum four distinct levels of meaning: (a) literal, (b) analogical, (c) moral, and (d) anagogical. ${ }^{3-4}$ At the first or literal level, integrating ethics may involve using case studies and referencing codes from various professional societies. The questions posed to students might include: "Are you aware of the various codes?" and "Do such codes help in constructing answers to ethical dilemmas?" At the second or analogical level, integrating ethics may include challenges of students to identify the analogy between proposed ethical dilemmas in an engineering context and a personal case in their own life. At the third or moral level, integrating ethics may involve a careful consideration of moral reasoning theories. For example, students may be asked to propose a solution to an ethical dilemma using an Utilitarian ${ }^{5}$ or a traditional rights-based approach ${ }^{6}$ common to many Western societies. Lastly, at the highest or anagogical level, integration of ethics may involve a reflection upon the modern age of technology and a consideration of entirely different views towards technology. For example, making use of the work of Barbour ${ }^{7}$, students may be challenged to reconcile their views on technology and its uses with the following models: (a) technology as liberator, (b) technology as a threat, and (c) technology as instrument of power. The approach taken in the present work seeks to integrate ethics into the freshman year experience at different levels of meaning and to assess its effectiveness. So far, efforts have been made at the literal, analogical and moral levels.

One of the innovative features of undergraduate engineering education at the Watson School of Engineering is the common core instruction of all students in the freshmen year. The Division of Engineering Discovery and Design coordinates the core courses, providing the opportunity for students to develop the necessary skills to be

Proceedings of the 2004 American Society for Engineering Education

Annual Conference and Exposition Copyright C2004, American Society for Engineering Education 
successful in their subsequent years regardless of the discipline of engineering. In addition, the core instruction parallels the learning experiences of students in conventional engineering programs at other institutions including the engineering science programs at New York State community colleges in order to insure that students from all such programs can transfer seamlessly into the Watson School programs as upper classmen.

The focus of the freshmen year program is centered on the courses entitled Discovering Engineering I and II, a two semester sequence that integrates instruction in engineering graphics and design, computer applications and tools, oral and written communication skills. Considerable attention is also given to the development of problem solving skills (including both critical and creative thinking skill development), and academic survival skills (i.e. time management, test taking and test preparation). Additionally, students confront the value-laden nature of the engineering profession through a careful consideration of moral reasoning theories, professional and engineering ethics, and an examination of the impact of technology in societal and global contexts.

\section{Efforts at Integration}

In Watson 111, consideration of ethics begins with an introduction to the existence of engineering codes set forth by the various professional engineering societies corresponding to engineering majors available at Binghamton. This is immediately followed by readings, lectures and in-class discussions of formal moral reasoning theories including Utilitarianism, Kantianism, rights and virtue based theories. Two different video/DVD presentations have been used to lay the foundations for ethics case studies, Gilbane Gold $^{8}$ and Incident at Morales. ${ }^{9}$ The companion study guides for the videos have proven to be an invaluable resource. Students are then asked to prepare a formal written response to one of the ethical dilemmas prepared in each of the videos. As the students are freshman, it is necessary to reinforce an important restriction on their responsespersonal opinions are neither sought nor acceptable but rather reasoned responses based on one of the included moral theories are required.

In Watson 112, problem-solving techniques are placed in the context of the impact of engineering and technology upon the environment. For example, students are exposed to conservation laws and asked to apply them to problems associated with automobile emissions and efficiency and battery recycling and disposal. References are then made when appropriate to the moral reasoning theories discussed in the fall.

Perhaps the element in the class that helps students best understand the importance of ethics in the engineering profession and the provided the unifying element has been the term design project with both a final presentation and a final report required. Projects are screened to insure that the many disparate components of the class, including working in a design team, graphical representation (freehand or computer-aided) of the design, a formal engineering design report including an ethical analysis, are all included. Over the course of the past three years, several different design projects have been assigned. Students have designed a host of different devices including a bicycle-parking

Proceedings of the 2004 American Society for Engineering Education

Annual Conference and Exposition

Copyright C2004, American Society for Engineering Education 


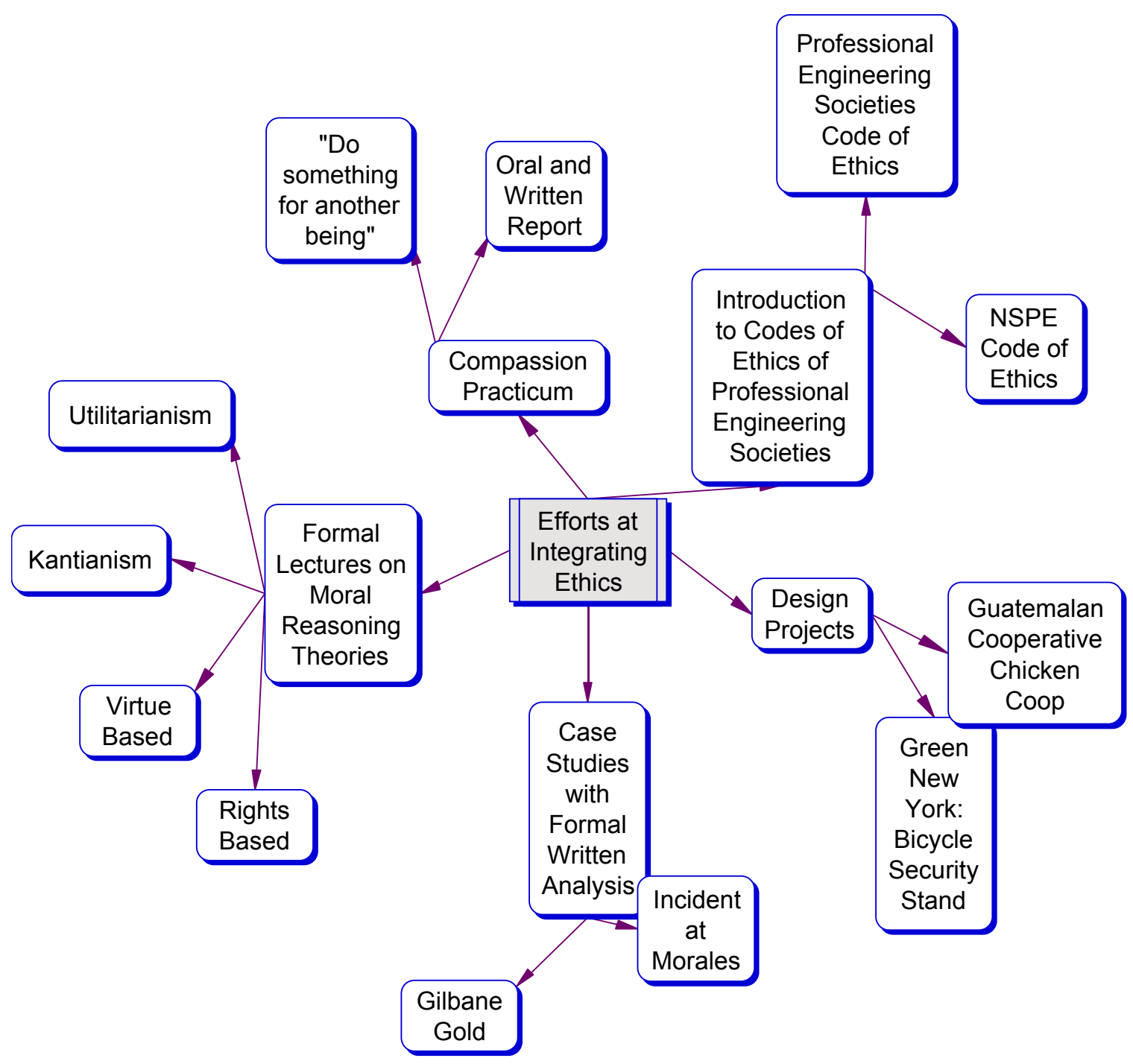

Figure 1. Efforts at Integrating Ethics in to Freshman Engineering

stand for use in New York City as part of a citywide design competition and a chicken coop for a farm cooperative in Guatemala. An integral part of the assignment consists of identifying ethical issues in the design. For example, with respect to the bicycle-parking stand, students were asked to consider the effect of technologies such as the automobile on the environment as well as to consider materials related issues such as waste disposal, reuse and recycling.

Proceedings of the 2004 American Society for Engineering Education Annual Conference and Exposition

Copyright $\mathbb{C} 2004$, American Society for Engineering Education 


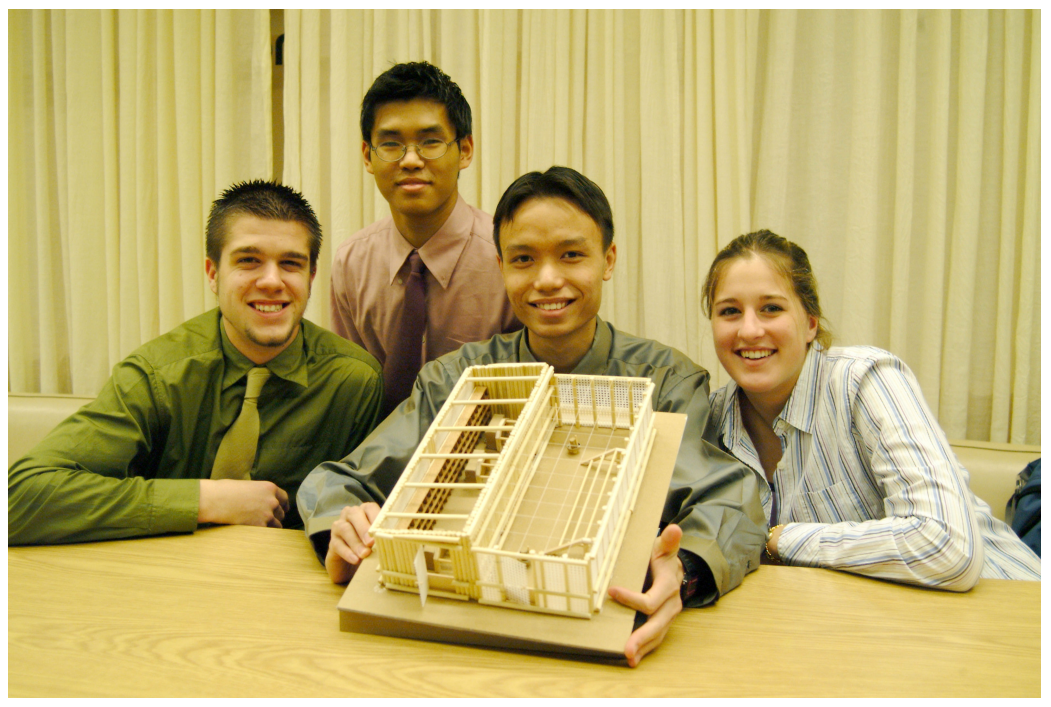

Figure 2. Example of Guatemalan Cooperative Chicken Coop Final Design

The chicken coop for a women's cooperative in Guatemala proved to be extremely effective as a mechanism for integrating ethics into freshman engineering. The problem, described by Dym and Little, has been used in the E4: Introduction to Engineering Design course at Harvey Mudd College. ${ }^{10}$ Freshman students are asked to design a chicken coop, which would result in increased egg and chicken production with a minimal impact on local customs and societal practices as well as on the natural environment. A mock-up of the design solution in addition to a formal oral presentation and written design is required. At the start of the semester, the students' reaction was quite subdued if not hostile. Their immediate, beginning vision of engineering was more clearly focused upon hi-technology wizardry rather than on helping indigenous people in South America. As the semester proceeded, the interest and enthusiasm for the project grew inexorably so much that by the end of the term, discussions of the project both inside and outside of class dominated. The resentment of being asked to design something as lo-tech as a chicken coop for poor women in Latin America was replaced by a sense of accomplishment in making the world a little bit kinder, gentler place, paraphrasing the thoughts of Aeschylus.

In addition to design projects focused on engineering, a project entitled, Compassion Practicum, has also been tried. ${ }^{11}$ A practicum is defined in the dictionary as "the part of the course that deals with practical work." Compassion from its Latin roots means "sharing the same blood or feelings." To be compassionate according to Native American mythology can be described as truly "being in another's shoes." A Compassion Practicum then is a practical work that demonstrates willingness to make a difference in a positive way in the world wherein action is the key, operative word. Students are offered a chance to do something for some living being and to get college credit for it. The projects are treated as design projects, requiring the implementation of the same design algorithms used in the more traditional design projects such as the chicken coop or bicycle stand. There are several parts to Compassion Practicum design project:

Proceedings of the 2004 American Society for Engineering Education

Annual Conference and Exposition

Copyright C 2004, American Society for Engineering Education 
- Students submit in the form of a typed, brief paragraph the project that they will complete. The recipient(s) and the specific task to be accomplished are stated.

- On the last day of class of the term, students prepare a short briefing focused on what was done, how it was received and the resultant feelings. The briefings are limited to 5 minutes.

- Also on the last day of class, a typed two-page document describing the project and resultant reactions is submitted.

Students over the past three years have completed a variety of different projects including the following:

- Working at a local homeless shelter

- Working at a local humane society and/or animal shelter

- Walking/running in a fund raising road race for some specific issue

- Taking a family member to lunch

- Visiting with patients who are in hospice care

- Visiting with residents of senior citizen homes

- Designing and building an accessible aquarium for a roommate who is paraplegic.

Students are challenged to pick something that they care passionately about and to act on those held passions with the emphasis on action.

\section{Discussion}

Assessment of the effectiveness of attempts at integrating ethics into the freshman engineering courses has proven to be very difficult. Here is what can be stated:

- Freshman students respond to the ethical issues raised in the case studies at very different levels of maturity. Approximately one third of the students never are moved from their decision to respond based solely upon their opinions, that is, what they personally think is right or wrong. Thus, ethics cases for them become nothing more than a test of personal wills or prejudices. Approximately one third of the students make at least some attempt at using one of the moral reasoning theories in defense of their positions while the remaining third argues persuasively, stating their position, describes the opposing view and then examines shortcoming of that opposing view.

- Design projects have proven to be an effective mechanism for generating discussion of ethical issues, in our case, issues related to the impact of technology on the environment and on indigenous cultures and traditions. There is clearly disappointment by some students, however, when the design project is not focused upon advanced technological wizardry.

- The Compassion Practicum has the most visible effect on the students. During the day of the final presentations, the classroom atmosphere is invariably quiet, almost reverential. Many are profoundly moved by the acts of selflessness, kindness and love, which their classmates share.

\section{References}

Proceedings of the 2004 American Society for Engineering Education

Annual Conference and Exposition Copyright C2004, American Society for Engineering Education 
1. Criteria for Accrediting Engineering Programs, ABET, Engineering Accreditation Commission, November 2, 2002, pp.1-2.

2. Shirley, D., “Avoiding Engineering Hubris,” ASEE Prism, April 2003, p.52

3. Eco, U., The Open Work, Harvard Univ. Press: Cambridge, Mass., 1989, pp.2527.

4. Dante Alighieri, Epistula XIII (to Cangrange della Scala): James Marchand, University of Illinois: http://ccat.sas.upenn.edu/jod/cangrande.english.html

5. Schinzinger, R. and Martin, M., Introduction to Engineering Ethics, McGrawHill: New York, 1999.

6. McGinn, R.E., "Technology, Demography, and the Anachronism of Traditional Rights," Society, Ethics and Technology, ed. Morton Winston and Ralph Edelbach, Wadsworth Group/Thomson Learning: Belmont, Ca., 2003, pp.136148.

7. Barbour, Ian, Ethics in an Age of Technology, The Gifford Lectures, Vol. 2, Harper Collins Publishers: San Francisco, 1993, pp.3-25.

8. Gilbane Gold, National Society of Professional Engineers, 1989.

9. Incident at Morales, National Institute for Engineering Ethics, Lubbock, Texas, 2003.

10. Dym, C.L., and Little, P., Engineering Design: A Project Based Introduction, John Wiley \& Sons: New York, 2000, pp.83-107.

11. Fox, Matthew, A Spirituality Named Compassion: Uniting Mystical Awareness with Social Justice, Inner Traditions Intl Ltd, October 1, 1999.

Proceedings of the 2004 American Society for Engineering Education Annual Conference and Exposition

Copyright C 2004 , American Society for Engineering Education 